\title{
THE APPROPRIATE USE OF THE VANCOUVER REFERENCING STYLE IN SCIENTIFIC PAPERS PUBLISHED IN BIOMEDICAL JOURNALS
}

\section{PRAVILNA UPOTREBA VANKUVERSKOG CITATNOG STILA U NAUČNIM RADOVIMA OBJAVLjENIM U BIOMEDICINSKIM ČASOPISIMA}

\author{
Dejan Živanović ${ }^{1}$, Jovan Javorac ${ }^{2}$
}

\section{SUMMARY}

Appropriate literature citation in scientific articles is a necessary and extremely important segment in the writing of any scientific paper. In modern science, referencing is accepted as a standardized method for displaying sources of scientific information and ideas which made the basis for author's scientific work, accomplishing that in a unique way that must identify their scientific origin, without any potential doubt. Since its establishment in 1978, Vancouver referencing style has become one of the most commonly used uniform methods for citing literature in scientific papers in the field of biomedicine, also known as the "author-number system". Considering all the advantages of Vancouver citing method and its presence in biomedical scientific journals, the aim of this paper is to provide readers with precise and clear instructions for its correct use in the writing of the scientific text intended for publication.

Keywords: citing, Vancouver referencing style, scientific paper, biomedicine

\section{Uvod}

Osnovna svrha bavljenja naukom i naučno-istraživačkim radom jeste rešavanje uočenog naučnog problema objektivnim, preciznim, pouzdanim i proverenim naučnim metodama, u cilju dodavanja novih, ili proširivanja već postojeće sume sistematizovanih naučnih saznanja iz određene naučne oblasti $(1,2)$. Međutim, nova naučna saznanja sama po sebi suštinski ne bi imala nikakvu vrednost, ukoliko ne bi bila prezentovana široj naučnoj javnosti, što je jedna od osnovnih i podrazumevanih etičkih dužnosti svakog naučnog radnika $(3,4)$. U današnje vreme, objavljivanje rezultata naučno-istraživačkog

\section{SAŽETAK}

Pravilno navođenje literature u naučnim člancima predstavlja neophodan i izuzetno važan segment u pisanju svakog naučnog rada. U savremenoj nauci, citiranje je prihvaćeno kao standardizovani metod prikazivanja izvora naučnih informacija i ideja koje su autoru poslužile kao osnova za naučnoistraživački rad, i to na jedinstveni način koji mora nedvosmisleno da identifikuje njihovo originalno naučno poreklo. Vankuverski citatni stil, od njegovog usvajanja 1978. godine do danas, jedan je od najčešce primenjivanih uniformnih načina za citiranje literature u naučnim radovima iz oblasti biomedicine, poznat i pod nazivom "sistem autor-broj". Imajući u vidu sve prednosti i zastupljenost Vankuverskih pravila za citiranje u biomedicinskim naučnim časopisima, cilj ovog rada je da čitaocima pruži precizna i jasna uputstva za njihovu pravilnu primenu u naučnim tekstovima koji su namenjeni za publikovanje.

Ključne reči: citiranje, Vankuverski citatni stil, naučni rad, biomedicina

rada i drugih naučnih informacija, značajno je pojednostavljeno globalnom upotrebom savremenih informatičkih tehnologija, koje u velikoj meri olakšavaju prezentovanje naučnog rada u naučnim publikacijama različitog tipa i formata. Objavljivanjem radova prati se rad naučnog radnika, ali se ujedno sprečava plagijarizam i širenje kvazinauke, neželjenih posledica savremene trke za prestižom u naučnim krugovima, koje mogu imati dalekosežne negativne posledice za nauku u celini. Upravo zbog pomenutog razloga, pri pisanju naučnih radova, neophodno je da se autori uvek pozivaju na literaturu koja je bila osnova za naučno-istraživački rad, kako u samom tekstu rada, tako i u datom popisu korišćenih liter-

\footnotetext{
${ }^{1}$ College of vocational studies for the education of preschool teachers and sport trainers, Dept. of biomedical sciences, Subotica, Serbia (Katedra za biomedicinske nauke, Visoka škola strukovnih studija za obrazovanje vaspitača i trenera, Subotica, Srbija)

${ }^{2}$ Institute for pulmonary diseases of Vojvodina, Sremska Kamenica, Serbia (Institut za plućne bolesti Vojvodine, Sremska Kamenica, Srbija)
} 
aturnih izvora. Primenom doslovnog citiranja ili pozivanja na misli, ideje i naučne rezultate drugih autora, istraživač ispunjava jedan od najvažnijih formalnih preduslova bavljenja naučnim radom, a to je intelektualno poštenje (5). Doslednim citiranjem korišćenih naučnih izvora u radu koji objavljujemo, ne samo da odajemo počast i zahvalnost autorima radova koje smo koristili pri izradi i pisanju sopstvenog naučnog rada, već neposredno indikujemo i stepen naučnog kvaliteta korišćenih publikacija $(6,7)$. Suštinski, citiranje korišćene literature treba jasno da navede čitaoca naučne publikacije na moguće načine provere opisanih metoda rada i rezultata istraživanja, kao i na sve dodatne neophodne informacije koje mogu da unaprede naše istraživanje. Jedino nije neophodno citirati tzv. ,opšte poznate naučne informacije" koje ne zahtevaju dodatno naučno tumačenje od strane drugih stručnjaka koji se bave naznačenom oblašću nauke (8). Danas je u upotrebi više stilova citiranja u biomedicinskim naukama, u zavisnosti od naučne oblasti ili zahteva i uputstava različitih naučnih časopisa, a jedan od najčešće korišćenih načina citiranja i navođenja literature u medicinskim publikacijama je svakako numerički, odnosno Vankuverski stil citiranja. Cilj ovog rada je da pruži relevantne informacije budućim autorima naučnih radova kako da citiraju literaturu korišćenjem Vankuverskog stila citiranja.

\section{Opšte karakteristike i specifičnosti primene Vakuverskog citatnog stila}

Potreba za citiranjem se javila kao logičan rezultat primene pravila koja vladaju u svetu savremene nauke. Zaštita autorstva je jedini način čuvanja intelektualne svojine i pravni mehanizam garancije intelektualnog poštenja. Svaki istraživač koji je objavio naučni rad treba da snosi odgovornost za sadržinu rada i rezultate koje je publikovao, bez obzira da li će mu oni doneti kritike ili priznanja naučne javnosti. Upravo zbog toga, citiranje je danas prihvaćeno kao „standardizovani metod prikazivanja izvora informacija i ideja koje se koriste u pisanju naučnog rada, $i$ to na jedinstveni način koji identifikuje njihove izvore" (8). Pravilnim citiranjem, odnosno navođenjem korišćenih zaštićenih izvora informacija, autor publikovanog rada izbegava mogućnost da bude optužen za plagijarizam krađu tuđeg intelektualnog vlasništva, koje se u kvazinaučnim radovima najčešće može sresti u obliku simulacije parafraziranja, krađe teksta, ili krađe ideja i metoda (9). Navođenje korišćene literature obavezno treba koristiti u uvodu, metodologiji i diskusiji naučnog rada, ali ne u poglavlju u kom se iznose rezultati istraživanja, kao i u sažetku, odnosno apstraktu rada, i zaključku (6).

Jedan od prvih uniformnih stilova citiranja koji je prihvaćen u naučnoj javnosti je Vankuverski citatni stil. Čak i nakon niza revizija, ovaj numerički postupak bibliografskog opisa korišćenih dokumenata je danas jedan od najčešće korišćenih, $i$ to ne samo $u$ biomedicinskim, već i u drugim prirodnim naukama, naročito u fizici. Ovaj citatni stil je dobio naziv po istoimenom gradu u kome je 1978. godine kreiran od strane radne grupe za unifikaciju načina citiranja u biomedicinskim časopisima, a koja je u međuvremenu prerasla u Međunarodni komitet urednika medicinskih časopisa (eng. International Committee of Medical Journal Editors, ICMJE). Iako je osnovna svrha njihovog kreiranja bila stvaranje uniformnih pravila citiranja i navođenja izvora literature, Vankuverska pravila su od samog početka definisala i kriterijume za uređivanje naučnih radova, ali i podrazumevane etičke norme kojih treba da se pridržavaju svi istraživači prilikom pisanja i publikovanja istih $(10,11)$. Ubrzo nakon usvajanja Vankuverskih pravila citiranja, i srpski časopisi iz oblasti biomedicine su ih prihvatili kao standard uređivanja naučnog rada za objavljivanje, prvo „Medicinski pregled” Društva lekara Vojvodine Srpskog lekarskog društva (1985), a nedugo zatim ,Srpski arhiv za celokupno lekarstvo" i drugi časopisi iz oblasti medicinskih nauka (6).

Vankuverski stil citiranja podrazumeva da se korišćena literatura navodi u radu najmanje dva puta - u tekstu rada i u popisu referenci $(1,6)$. Citati se prvo označavaju u samom tekstu rada arapskom cifrom u zagradi ili superskriptom, od jedan pa nadalje, a zatim se na kraju rada daje detaljan bibliografski opis korišćene literature (tzv. „sistem autor broj"). Ukoliko se navedeni literaturni izvor u daljem tekstu ponovo koristi, citat uvek treba označiti istim brojem pod kojim je prvi put označen. Obaveza autora je da na kraju rada navede popis korišćene literature, i to onim redosledom kojim su se one pojavljivale u tekstu $(6,9)$. Važno je naglasiti da citiranje uvek treba jasno da uputi čitaoca u korišćenu literaturnu građu, a nikako da ga dovede u zabludu, odnosno ,pravilno citiranje treba da otkrije autorove izvore, ne da ih sakrije" (8). 


\section{Primena Vankuverskog citatnog stila u naučnom radu pripremljenom za objavljivanje}

Prema Vankuverskim pravilima, navođenje literature $u$ radu treba da ukaže na snagu novih naučnih saznanja, ističući ranija saznanja o navedenom naučnom problemu i dovodeći ih u korelaciju sa rezultatima novog istraživanja (10). Navodi iz citirane literature mogu se koristiti na dva načina - parafraziranjem ili doslovnim navođenjem rečenice, odnosno dela teksta. Parafraziranje je uvek poželjniji način navođenja u naučnim radovima, i podrazumeva prenošenje suštinskog smisla neke naučne informacije, odnosno informacijskog sadržaja iz korišćenog literaturnog izvora, uz neophodno zadovoljavanje uslova verodostojnosti, i u skladu sa ciljem sopstvenog teksta i korišćenjem sopstvenih stilističkih sredstava (12). Parafrazirani navodi su obično slične dužine kao i originalni tekst ili kraći, ne obeležavaju se navodnicima, ali to i dalje obavezuje autora da citiranjem literature uputi čitaoca na originalan izvor informacija, pisanjem arapske cifre u malu zagradu (četvrtastu ili uglastu, u zavisnosti od zahteva časopisa) na kraju parafraziranog dela teksta. Nepravilno izvedeno parafraziranje naučnog teksta i dalje predstavlja jedan od najčešćih vidova plagijarizma u naučnim radovima, bilo namernog ili nenamernog, zbog čega većina časopisa u svojim uputstvima za autore jasno ističe da se parafrazirani tekst mora dovoljno razlikovati od originalnog, a istovremeno i jasno ukazivati na njegovo poreklo $(12,13)$.

U tekstu rada se mogu koristiti i doslovna navođenja rečenica ili delova teksta iz drugih naučnih radova. Doslovno prenošenje zaštićenog izvora informacija predstavlja standardizovan postupak u naučnim radovima kojim se u neizmenjenom obliku u sopstveni rad unosi tekst ili neki drugi oblik intelektualne svojine drugog autora (12). Upotreba do šest reči iz originalnog teksta u nizu ne mora biti označena navodnicima, ali se citati duži od šest reči, a kraći od 40, obavezno moraju označiti znacima navoda. Vankuverska pravila nalažu da citate koji su duži od 40 reči uvek treba izdvojiti u radu kao poseban deo teksta koji je jasno odvojen kurzivom ili uvlačenjem pasusa od ostatka rukopisa $(12,14)$. Ukoliko je autor rada naišao na neku identičnu tvrdnju ili identične rezultate istraživanja u više radova, iste navodi u zagradi kao reference u nizu, odvojene zarezom $(6,15)$. Jedna od najčešćih (početničkih) grešaka istraživača je izbegavanje citiranja publikacija čiji su re- zultati suprotni rezultatima koje je dobio sam istraživač. Navođenje ovih naučnih radova ne umanjuje vrednost realizovanog istraživanja, naprotiv, u naučnim krugovima ovakav postupak se smatra znakom kritičkog razmišljanja i intelektualnog poštenja istraživača.

Prevođenje originalnog teksta napisanog na stranom jeziku treba primenjivati obazrivo. Preporuka je da se prevod uvek prepusti profesionalnom prevodiocu, jer postoji objektivna opasnost da prevedeni naučni tekst dobije drugačiji naučni smisao od originalnog. Korišćenje prevoda originalnog teksta $u$ pisanju naučnog rada bez označavanja literaturnog izvora se takođe smatra plagiranjem. Štaviše, ukoliko pravila časopisa to dozvoljavaju, prevedeni deo teksta uvek treba navesti i na originalnom jeziku u fusnoti (15).

Osim doslovnog citiranja, danas je često u upotrebi i tzv. „sekundarno citiranje“, odnosno navođenje informacija iz radova kojima autor nema direktan pristup, već je do njih došao posredstvom drugih publikacija u kojima su ti radovi korišćeni kao literaturni izvor. Ovakav način korišćenja naučnih informacija treba izbegavati kad god je to moguće. Preporučuje se traženje originalnog rada, a kada to nije moguće, treba citirati publikaciju iz koje je informacija u tom obliku preuzeta (12). Treba napomenuti da citiranju ne podležu samo parafrazirani ili doslovno i sekundarno preuzeti delovi akademske građe korišćenih izvora, već i svi drugi oblici publikovanih zaštićenih informacija (tabele, grafikoni, sheme, crteži, fotografije i sl.), uključujući i elektronske izvore informacija. Takođe, navođenje podataka ili teksta iz sopstvenih, prethodno publikovanih radova u izvodu ili celini, bez navođenja literaturnog izvora, takođe se smatra (auto) plagijarizmom. Ukoliko autor citira svoj prethodni rad (autocitat), dužan je da to označi na isti način kao i radove drugih autora.

\section{Sastavljanje liste korišćene literature prema Vankuverskim pravilima}

Prikaz korišćenih literaturnih izvora se uvek navodi na kraju rada u posebnom poglavlju označenom podnaslovom, a arapski broj koji je naveden ispred literature u ovom poglavlju mora odgovarati broju literature koji je naveden u tekstu rada. Literatura se obavezno numeriše na osnovu redosleda pojavljivanja u tekstu (14). Navod naučnog izvora koji je korišćen prilikom izrade rada treba da sadrži potpuni bibliografski opis korišćenog zaštićenog informacijskog sadržaja koji će čitaoca jasno uputiti na prikazani izvor: 
prezime i prvo slovo imena autora (ili više njih), tačno naveden naziv publikovanog rada (članak u časopisu, knjiga, monografija i sl.), kao i podatak gde, kada i koji izdavač je publikovao citirano delo. Prikaz korišćene literature takođe može biti predmet plagiranja. Popis literature treba da bude autentičan za svaki rad. Korišćenje popisa literature iz drugih radova ne samo da nije u skladu sa etičkim pravilima koje svaki autor mora da poštuje pri izradi i publikovanju naučnog rada, već u biomedicinskim naučnim krugovima može i direktno ili indirektno uticati na zdravlje ljudi, širenjem neistinitih ili neproverenih, kvazinaučnih informacija $(6,10)$. Osnovna pravila za citiranje bibliografskih jedinica Vankuverskim stilom uključuju:

-pravilno korišćenje punktuacije u navođenju reference,

-primenu preporučenog redosleda u prikazu detalja bibliografske jedinice,

-navođenje prezimena i početnog slova imena svih autora; ukoliko je u pisanju publikacije učestvovalo više od šest autora, navodi se prvih šest i dodaje skraćenica "et al", odnosno ,i dr" (,,i dr"),

-bibliografsku jedinicu treba prikazati latiničnim pismom kad god je to moguće,

-navođenje skraćenog naziva časopisa prema Listi indeksiranih časopisa u Medline-u (List of Journals Indexed for Medline, Index Medicus),

-navođenje potpunog naziva časopisa, ukoliko nije indeksiran u Medline-u,

-navođenje abrevacija naziva domaćih časopisa koji nisu indeksirani u gore pomenutoj listi, a na osnovu Liste skraćenih naziva srpskih serijskih publikacija (Srpski citatni indeks/Srpski citatni indeks, SCIe indeks),

-ukoliko se aktuelni rad objavljuje u časopisu na engleskom jeziku, poželjno je prilikom citiranja onih radova koji nisu objavljeni na tom jeziku, u popisu literature koristiti naslov rada na engleskom jeziku pod kojim je isti dostupan, pored koga u maloj zagradi treba napisati na kom jeziku je rad izvorno objavljen (npr. Serbian),

-kod pisanja broja stranica ne treba ponavljati iste cifre za iste dekadne jedinice (npr. ne treba pisati 216-223, već 216-23),

-na kraju navođenja literature uvek treba staviti tačku, i

-za navođenje radova koji su prihvaćeni za publikovanje, ali još nisu objavljeni, treba koristiti naznaku „In press” ili „Forthcoming” $(6,8)$.

$\mathrm{Na}$ kraju, svakako treba pomenuti da danas postoje i različiti, specijalno dizajni- rani softveri za uvođenje novih i uređivanje već postojećih izvora koji su citirani u tekstu, čime je autorima značajno olakšana korekcija citirane literature u naučnom radu - Reference Manager, Refworks, Mendeley, EndNote (16). Pravilno navođenje različitih bibliografskih jedinica Vankuverskim stilom u radovima iz oblasti biomedicine (17), može se naći na sledećim adresama:

\section{1) Citiranje standardnog rada u časopisu:}

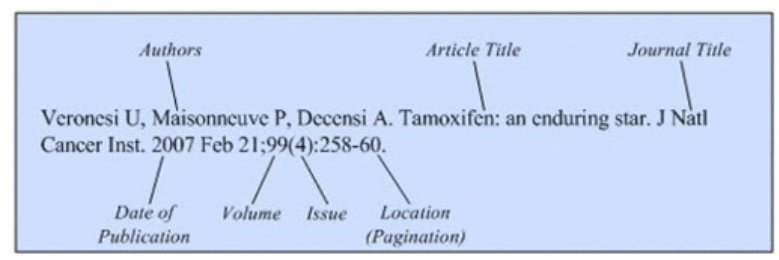

preuzeto: https://www.ncbi.nlm.nih.gov/ books/NBK7282/\#A32362

2) Citiranje neobjavljenog rada koji je prihvaćen za publikovanje:

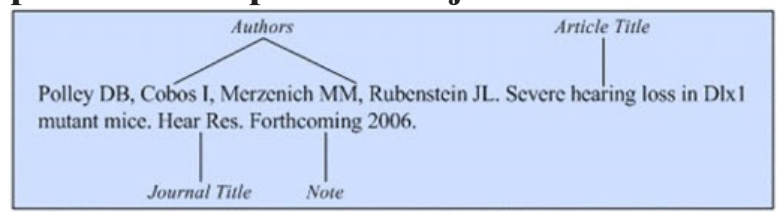

preuzeto: https://www.ncbi.nlm.nih.gov/ books/NBK7240/\#A42793

\section{3) Citiranje tabele iz objavljenog rada u časopisu:}

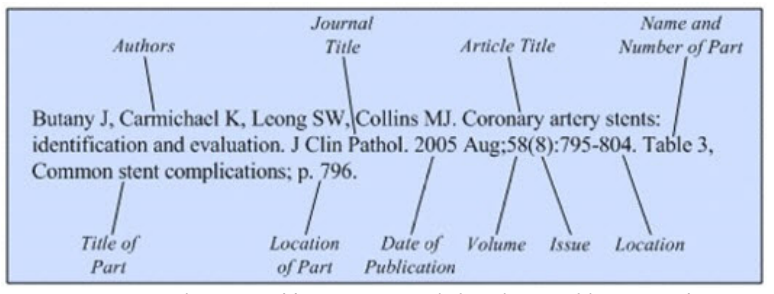

preuzeto: https://www.ncbi.nlm.nih.gov/ books/NBK7282/\#A32756

\section{4) Citiranje rada objavljenog u elektrons- kom časopisu:}

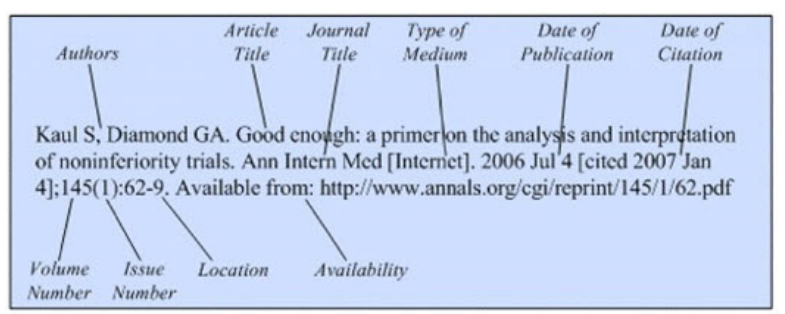

preuzeto: https://www.ncbi.nlm.nih.gov/ books/NBK7281/ 


\section{5) Citiranje knjige u celini:}

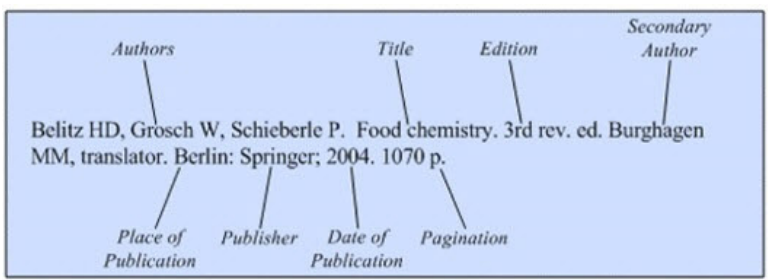

preuzeto: https://www.ncbi.nlm.nih.gov/ books/NBK7271/

\section{6) Citiranje dela knjige:}

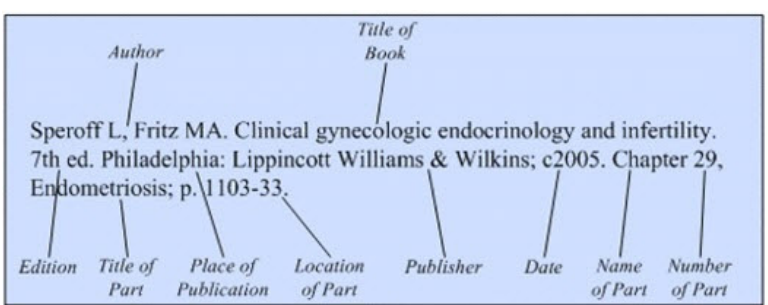

preuzeto: https://www.ncbi.nlm.nih.gov/ books/NBK7271/\#A34794

\section{7) Citiranje poglavlja u knjizi:}

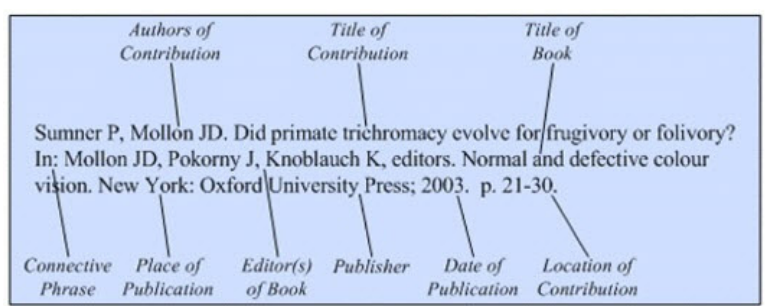

preuzeto: https://www.ncbi.nlm.nih.gov/ books/NBK7271/\#A34915

\section{8) Citiranje cele knjige koja je objavljena} na Internetu:

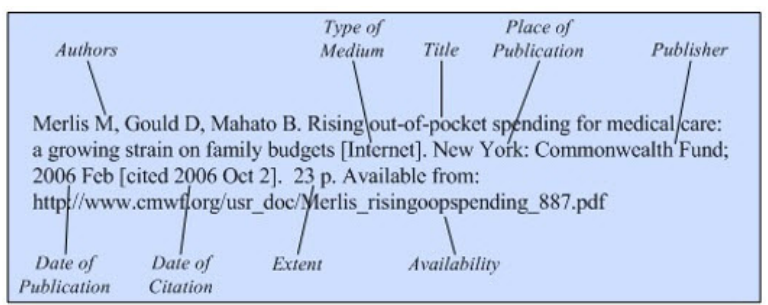

preuzeto: https://www.ncbi.nlm.nih.gov/ books/NBK7269/

\section{9) Citiranje objavljene disertacije:}

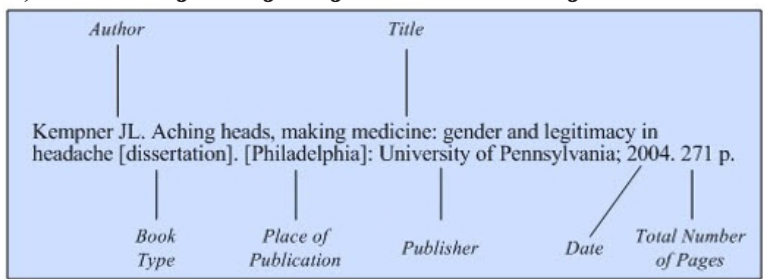

preuzeto: https://www.ncbi.nlm.nih.gov/ books/NBK7267/
10) Citiranje rada sa održanog naučnog skupa u zborniku sa i bez posebnog naziva:

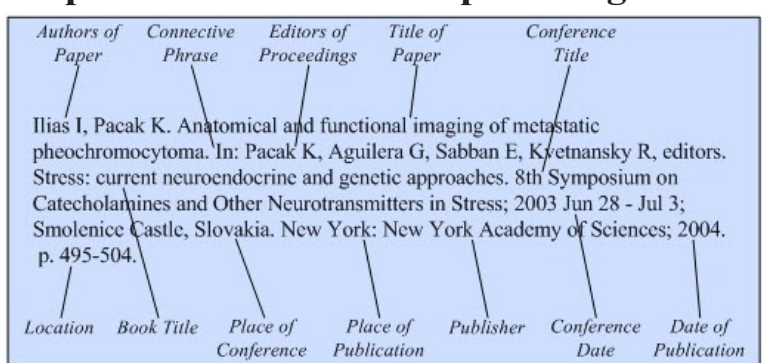

Authors of Editors of
Paper Proceedings
Rice AS, Farquhar-Smith WP, Bridges D, Brooks JW. Canabinoids and pain. In:
Dostorovsky JO, Carr DB, Koltzenburg M, editors. Proceedings of the 10th World
Congress on Pain; 2002 Aug 17-22; San Diego, CA. Scattle (WA): IASP Press;
c2003. p. 437-68.
$\begin{gathered}\text { Date of Location Conference } \\ \text { Publication }\end{gathered}$
Date

preuzeto: https://www.ncbi.nlm.nih.gov/ books/NBK7272/\#A37022

\section{1) Citiranje poster prezentacije sa naučnog skupa:}

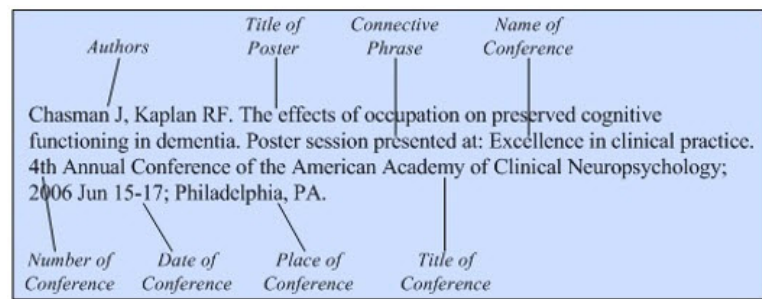

preuzeto: https://www.ncbi.nlm.nih.gov/ books/NBK7255/

\section{2) Citiranje web stranice na Internetu:}

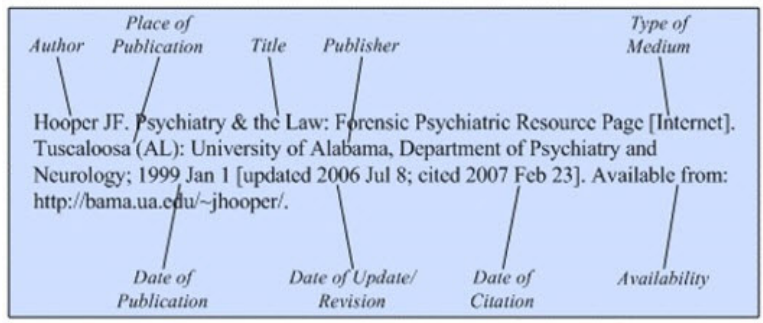

preuzeto: https://www.ncbi.nlm.nih.gov/ books/NBK7274/

13) Citiranje otvorene i zatvorene baze podataka na Internetu:

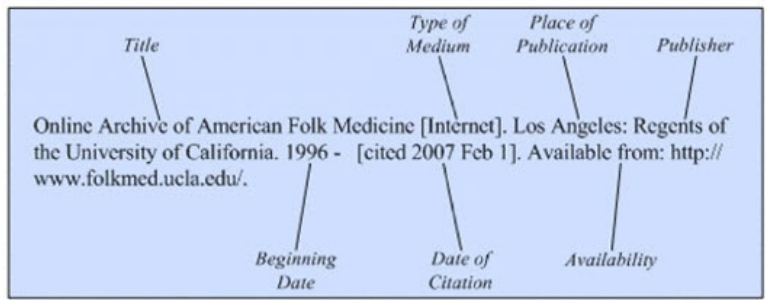




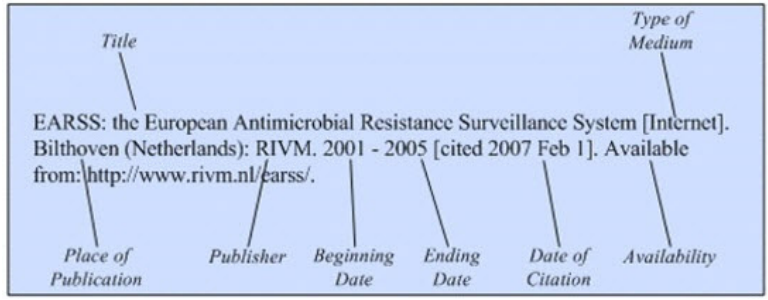

preuzeto: https://www.ncbi.nlm.nih.gov/ books/NBK7273/

\section{Zaključak}

Navođenje tuđih radova prilikom pisanja naučnog rada realizuje se prema standardizovanim postupcima sa ciljem jasnog, poštenog i naučno prihvatljivog upućivanja čitalačke publike na izvore informacija, kao i sprečavanja plagijarizma i štetnih efekata širenja kvazinaučnih informacija. Jednostavnost upotrebe i mogućnost detaljnog sprovođenja citatne analize naučnih tekstova koji su napisani primenom sistema ,autor broj", doveli su do toga da se Vankuverska pravila citiranja u savremenoj nauci svrstavaju među najčešće korišćene citatne stilove - ne samo u oblasti biologije, medicine i srodnih zdravstvenih nauka, već i u celokupnom akademskom stvaralaštvu.

\section{Literatura}

1. Bajkin B. Nauka i pseudonauka. In: Đurić P, ed. Uvod u naučnoistraživački rad. Novi Sad: Medicinski fakultet, 2004: p. 9-12.

2. Đurić M. Prezentacija naučnoistraživačkog rada. In: Đurić P, ed.. Uvod u naučnoistraživački rad. Novi Sad: Medicinski fakultet, 2004: p. 164-75.

3. Vučković Dekić Lj. Kako se piše naučno/stručni rad. Biomedicinska istraživanja 2014; 5(1):71-6.

4. Hetherington AM, Lennon S. Ethics in scientific publishing. New phytologist 2017; 213(1):5-6.

5. Vučković Dekić Lj, Radulović S, Stanojević Brkić N, Jelić S, Borojević N, Stojanović N et al. Etički kodeks naučnoistraživačkog rada - dobra naučna praksa. Stom Glas S 2007; 54:132-40.
6. Brkić S. Citiranje literature. Srp Arh Celok Lek 2013; 142(3-4):275-9.

7. Pasternak J. Vrednovanje naučnog dela. In: Đurić P, ed. Uvod u naučnoistraživački rad. Novi Sad: Medicinski fakultet, 2004: p. 136-45.

8. Milić N. Citiranje literature u naučnom radu [database on the Internet]. Beograd (SER): Medicinski fakultet Univerziteta u Beogradu - Medicina sporta (SER), c2018 [updated 2018 Aug 24; cited 2018 Dec 12]. Available from: http://www.medicinasporta.med. bg.ac.rs/wp-content/uploads/2018/02/Citiranje-literature-u-naucnom-radu.pdf

9. Kako citirati? Zagreb: Središnja medicinska knjižnica Medicinskog fakulteta Sveučilišta u Zagrebu, 2016: p. 1-11.

10. Berić L. Vankuverski stil: suvremeno citiranje autora u biomedicinskim časopisima. Acta Stomatol Croat 1986; 20(3):253-5.

11. Pears R, Shields G. Cite them right: the essential referencing guide. 10th ed. London: Palgrave, 2016: p. 153-9.

12. Janović T. Citiranje, parafraziranje i upućivanje na izvore u akademskim radovima (skripta). Zagreb: Hrvatski studiji Sveučilišta u Zagrebu, 2013: p. 8-16.

13. Mohan Kumar P, Swapna Priya N, Musalaiah SVVS, Nagasree M. Knowing and avoiding plagiarism during scientific writing. Ann Med Health Sci Res 2014; 4(3):193-8

14. Brkić S, Pejić M. Vankuverska pravila i objavljivanje radova u biomedicinskim časopisima. Med Pregl 1996; 49(1-2):27-31.

15. Kuzmanović Jovanović A, Andrijević M, Filipović J. Priručnik iz akademskog pisanja: uputstva i sugestije za pisanje seminarskih, naučnih, stručnih radova. Beograd: Čigoja štampa, 2012.

16. Basak SK. A comparison of researcher's reference management software: Refworks, Mendeley, and EndNote. J Econ Behav Stud 2014; 6(7):561-8.

17. Patrias K, author; Wendling D, editor. Citing Medicine: The NLM Style Guide for Authors, Editors, and Publishers [Internet]. 2nd edition. Bethesda (MD): National Library of Medicine (US), 2007 [cited 2018 Dec 17]. Available from: https://www.ncbi.nlm.nih. gov/books/NBK7256/

Conflict of interest: None declared.

Received (primljen): 08/15/2019

Revised (revizija): 09/17/2019

Accepted (prihvaćen): 09/20/2019

Online first: 09/30/2019

Kontakt: Dejan Živanović, Katedra za biomedicinske nauke, Visoka škola strukovnih studija za obrazovanje vaspitača i trenera, Banijska 67, 24000 Subotica, Serbija; e-mail: zivanovic_dejan@yahoo.com

Correspondence to: Dejan Živanović, College of vocational studies for the education of preschool teachers and sport trainers, Dept. of biomedical sciences, Banijska 67, 24000 Subotica, Serbia; e-mail: zivanovic_dejan@yahoo.com 